\title{
Large-Scale Fading and Time Dispersion Parameters of UWB Channel in Underground Mines
}

\author{
Abdellah Chehri, ${ }^{1,2}$ Paul Fortier, ${ }^{1,2}$ and Pierre Martin Tardif ${ }^{2}$ \\ ${ }^{1}$ LRCS Laboratory, 450 3rd Avenue, Val-d'Or, PQ, Canada J9P $1 S 2$ \\ ${ }^{2}$ Department of Electrical and Computer Engineering, Université Laval, Sainte-Foy, PQ, Canada G1K 7P4
}

Correspondence should be addressed to Abdellah Chehri, chehri@gel.ulaval.ca

Received 6 February 2008; Accepted 23 April 2008

Recommended by Miguel Ferrando

RF channel measurements in underground mines have important applications in the field of mobile communications for improving operational efficiency and worker safety. This paper presents an experimental study of the ultra wideband (UWB) radio channel, based on extensive sounding campaigns covering the underground mine environment. Measurements were carried out in the frequency band of 2-5 GHz. Various communication links were considered including both line-of-sight (LOS) and nonLOS (NLOS) scenarios. In this paper, we are interested in more details of the variations of the RMS delay spread and mean excess delay with Tx/Rx separation, and the variation of RMS with mean excess. The distance dependency of path loss and shadowing fading statistics is also investigated. To give an idea about the behaviour of UWB channel in underground mines, a comparison of our approach with other published works is given including path loss exponent, shadow fading variance, mean excess delay, and RMS delay spread.

Copyright (C) 2008 Abdellah Chehri et al. This is an open access article distributed under the Creative Commons Attribution License, which permits unrestricted use, distribution, and reproduction in any medium, provided the original work is properly cited.

\section{INTRODUCTION}

During the last years, a number of mining companies have invested in modern communications systems in order to increase the productivity, automate processes, and to reduce operational costs. Remote monitoring, video transmission at very high speed, and the extensive use of cellular phone technology are all of interest. Safety of miners is also a concern, regulated by health and safety regimes.

Underground communication systems still rely on analog technology. Digital upgrades modernize legacy technology using a coaxial cable to transmit important signals like voice, video, and telemetry. Therefore, all wired equipments can benefit from an increase in efficiency from digital technology.

However, when it comes to mobile equipment, the only medium is radio wave. Mobile RF communications is important in mining since it can improve operational efficiency and worker safety [1]. Successful RF communications require an understanding of the RF propagation channel in mine tunnels. A communication system in this environment is a convenience for daily activities. However, in emergencies, it may become vital. In a disaster, such as a fire, the conventional wire communication system may become unreliable, necessitating a wireless radio system.

Ultra-wideband is a radio communication technique using signals over an extremely wide frequency bandwidth, typically in the order of $500 \mathrm{MHz}$ to several GHz. This particularity may be exploited to develop communication systems with high-rate and low-rate wireless communications and localization capabilities [2].

The development of UWB communication systems has become an intensive research activity in both academic and industrial communities. A considerable amount of work has already been performed in this field, and a number of experimental sounding campaigns were set up in order to characterize the UWB propagation channel [3]. For instance, the IEEE 802.15.3a and IEEE 802.15.4a task groups developed UWB channel models for the simulation of systems proposed for standardization $[4,5]$. The analysis and design of an UWB communication system requires an accurate channel model to determine the maximum achievable data rate, to design efficient modulation schemes, and to study associated signal-processing algorithms. Hence, 
accurate channel characterization is necessary for UWB transceiver design and for efficient utilization of the system's resources such as frequency spectrum and transmit power. The propagation channel sets fundamental limits on the performance of UWB communication systems.

In this paper, characterization of some parameters of the UWB channel in underground mines are extracted such as mean excess delay and RMS delay spread. Large-scale modeling is an important characteristic for link budget calculation and system design. Hence, this parameter is also investigated in this paper. In the next section, we give details about the environment, the measurement campaigns, and the methodology used for data acquisition. The results on the analysis including large-scale modeling and time dispersion of UWB channel in underground mines are summarized in Section 3. We give a comparison of published results for UWB and wideband channels in Section 4. Section 5 concludes this paper.

\section{MEASUREMENT SETUP, ENVIRONMENT, AND METHODOLOGY}

The measurements campaigns were carried out in a real underground mine. This former gold mine is located approximately 530 kilometers north-west of Montreal and is now managed by MMSL CANMET (Mining and Mineral Sciences Laboratories-Canadian Center for Minerals and Energy Technology) in which tests and trials in field can be performed. The dimensions of the gallery varied between $2.5 \mathrm{~m}$ and $3 \mathrm{~m}$ in width and the height was about $3 \mathrm{~m}$, typical of a conventional mine.

Since we gave other details of the propagation experiments in other mine segments [6-8], we are going to summarize here only the fundamental issues of this paper. A vector network analyzer (VNA) was used to sound the radio channel following a classical $S_{21}$ parameter measurement procedure. The VNA recorded the variations of 1601 complex tones across the $2-5 \mathrm{GHz}$ frequency band. The resulting frequency resolution of $1.875 \mathrm{MHz}$ implied a maximum resolvable delay of 533 nanoseconds for the measured channel impulse response (CIR).

The static condition ensures that the impulse response of the channel does not vary during the time required for the VNA to collect all the needed data. The two ports of the VNA are connected to the transmitters and receivers antennas. An Electro-Metrics EM-6116 antenna is used both in transmission and reception (Figure 1).

The sounding signal was transmitted at a power level of $20 \mathrm{dBm}$. The antenna coaxial cables used in the measurements had been carefully chosen. The attenuation of the coaxial cable (STORM, True Blue) was found to be very high. The use of passive elements in the measurement apparatus (cables, SMA connectors, etc.) imposed systematic and frequent calibration measurements, in order to compensate undesirable frequency-dependent attenuation factors that could affect the collected data. Following the VNA manual's recommendations, the calibration through response type was selected, and the cables and the connectors were included in this calibration.

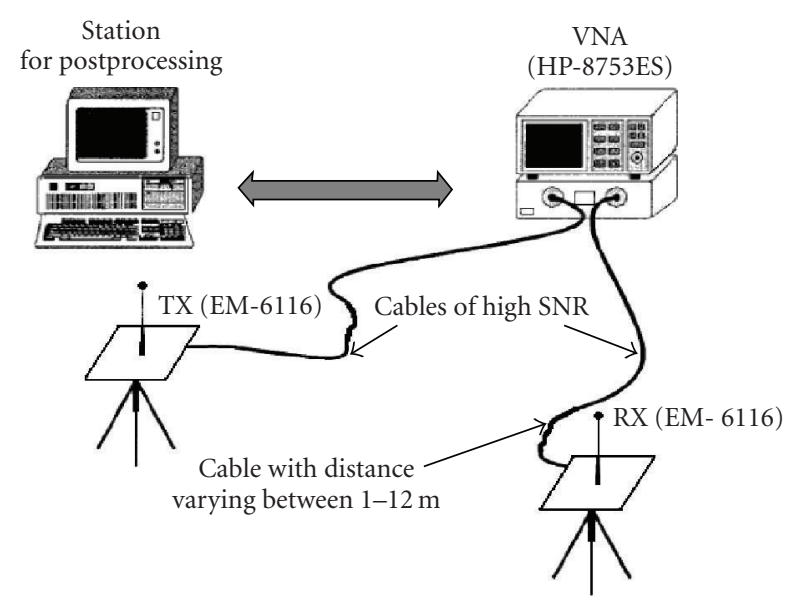

FIgURE 1: Channel measurement setup.

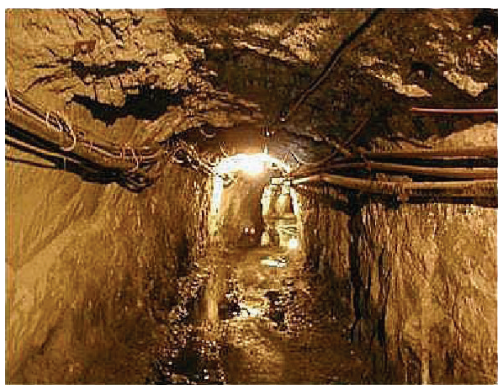

Figure 2: CANMET mine gallery-LOS case.

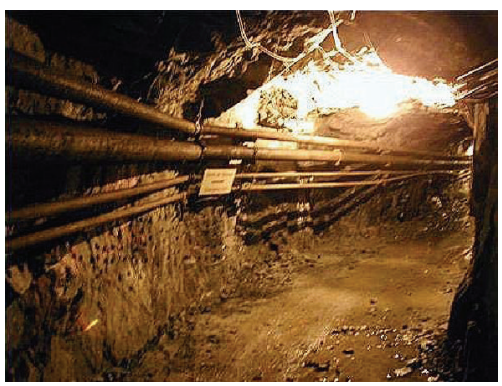

Figure 3: CANMET mine gallery-NLOS case.

The $\mathrm{Rx}$ antenna was placed at a height of about $1 \mathrm{~m}$. The Tx antenna was fixed at a height of $1 \mathrm{~m}$ and arranged in a $8 \times 5$ rectangular grid with $7 \mathrm{~cm}$ spacing, slightly smaller than half the wavelength at the lowest measured frequency $(2 \mathrm{GHz})$, to obtain approximately independent samples. Both line-of-sight (Figure 2) and nonline-of-sight (Figure 3) configurations were investigated.

As can be seen on Figures 2 and 3, the gallery walls have a significant roughness. The gallery constitutes a channel with multiple paths. Many obstacles are present (electric wires, ventilation systems, cables, and pipes located near the ceiling) and they act as more or less reflective surfaces for the 


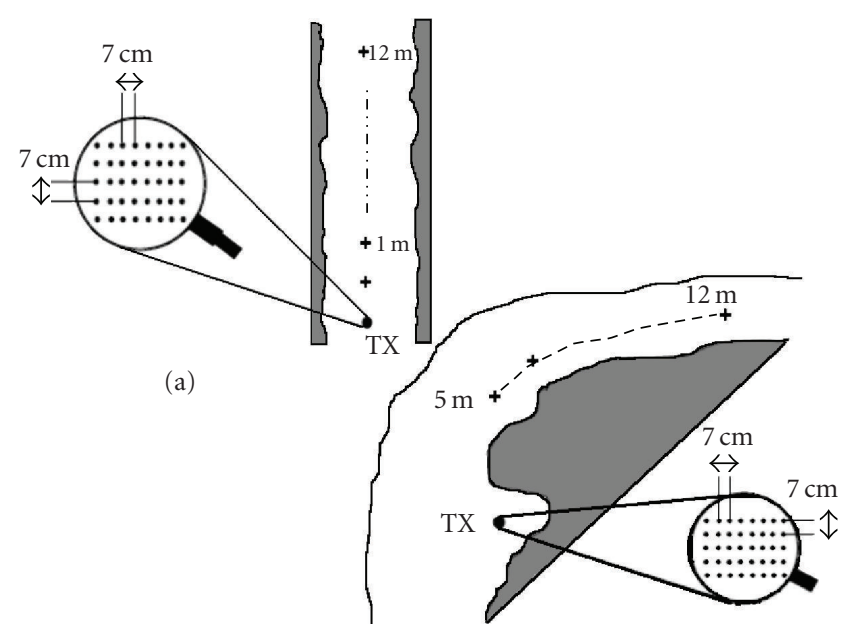

(b)

FIgURE 4: Transmitter/receiver positioning (a) LOS case, (b) NLOS case.

waves. The floor of the gallery is rather undulating and one can see water puddles of different sizes.

\subsection{Measurements for LOS case}

In this measurement campaign, the transmitting antenna remained in a fixed position whereas the receiving antenna was moved at variable distances going from $1 \mathrm{~m}$ up to $12 \mathrm{~m}$ with a $1 \mathrm{~m}$ step between measurements (Figure $4(\mathrm{a})$ ).

\subsection{Measurements for NLOS case}

This campaign was similar to the LOS case. However, because of the difficulty of placing the receiving antenna at close range, due to the topology of the mine, we started the measurements at $5 \mathrm{~m}$. A schematic diagram of the measurement setup is shown in Figure 4(b).

\section{MEASUREMENT DATA PROCESSING}

Extracting characteristic radio channel parameters from channel measurements and creating statistical channel models are a common method to assess the performance of air interface candidates in terms of error rates and outage probabilities. Thus the main objective of channel sounding is to correctly model the UWB channel. Consequently, if the multipath medium is well characterized, the transmitter and the receiver can be designed in order to decrease the effect of multipath fading.

\subsection{Large-scale modeling}

For UWB systems, it was reported that the path loss modeling can be simplified by assuming that the frequency dependence and the distance dependence can be treated independently of each other:

$$
P(f, d)=P L(f) \cdot P L(d) .
$$

However, $P L(f)$ was already analyzed in [6]. Hence, in this paper, we analyze the path loss distance dependence.

\subsubsection{Path loss distance dependence}

The path loss of the channel represents the attenuation a signal undergoes when transmitted through the medium. The frequency response obtained from the VNA was referenced to $1 \mathrm{~m}$ for LOS and $5 \mathrm{~m}$ for NLOS, as described in the measurement procedure. Using the measured frequency response data, the average path loss at any distance $d$ can be estimated using the following equation:

$$
P l(d)=\frac{1}{N M} \sum_{i=1}^{N} \sum_{j=1}^{M}\left|H\left(f_{i}, f_{j} ; d\right)\right|^{2}
$$

where $H\left(f_{i}, f_{j} ; d\right)$ denotes the $j$ th channel transfer function snapshot at frequency $f_{i}$ and at distance $d, N$ is the number of observed frequencies, and $M$ is the number of frequency response snap shots over time. It is well known that the mean path loss referenced to a distance $d_{0}$ can be modeled as a function of distance using:

$$
P l(d)=P l_{0}+10 n \log _{10}\left(\frac{d}{d_{0}}\right)+S(d), \quad d \geq d_{0},
$$

where $d_{0}$ is the reference distance, in our case $d_{0}=1 \mathrm{~m}$ for LOS $\left(d_{0}=5 \mathrm{~m}\right.$, for NLOS) and $P l_{0}$ is the interception point, $n$ is referred to as the path loss exponent, and $S$ is the shadowing fading parameter that varies randomly from one location to another.

Equation (3) was used to compute path loss for all of the individual power impulse response measurements and for each of the spatially averaged power impulse response.

In this paper, the average power for each measurement is calculated by averaging the power over all sample points of the measured frequency response. Using linear regression analysis, the minimum mean square error (MMSE) line is calculated for the dependence of average power $(\mathrm{dB})$ on the logarithm of the distance for each global experiment. The slope of the regression line gives the experimental value of $n$.

Figure 5 shows a scatter plot of received power $(\mathrm{dB})$ versus distance on a log scale for the measurement and the MMSE line fitted to the data. The linear regression analysis gives $n=1.47$ for LOS and $n=2.45$ for NLOS.

\subsubsection{Shadow fading}

Due to variations in the surrounding environments, $P L$ observed at any given location will deviate from its average value. This phenomenon is called shadow fading and has been reported by many measurements [9-15] to follow a lognormal distribution. In (4), the shadow fading parameter is 


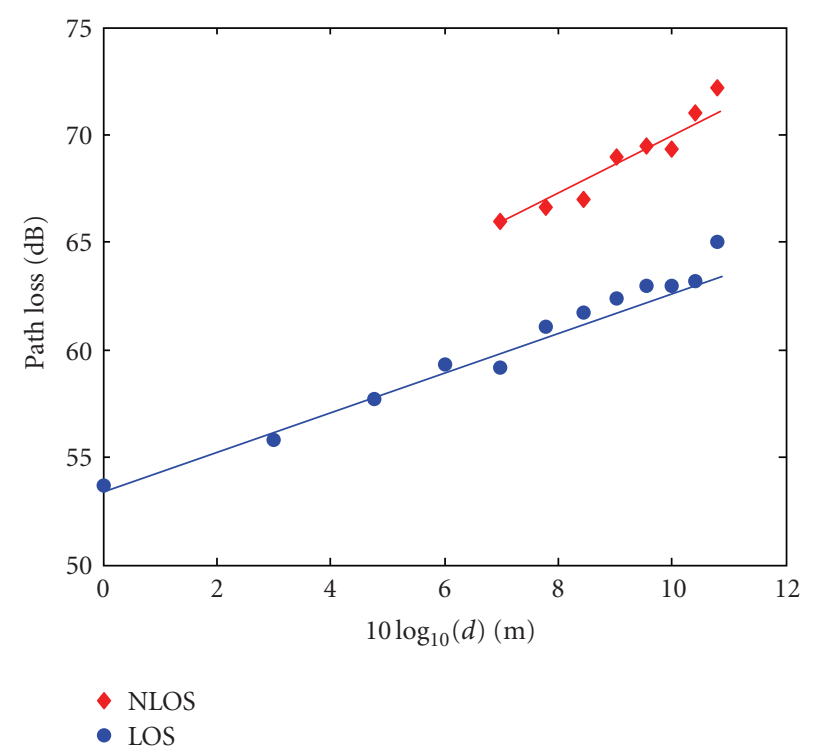

FIGURE 5: Scatter plot of path loss versus Tx/Rx separation distance.

given by the term $S$ that varies randomly from one location to another. It is a zero-mean Gaussian-distributed random variables in $\mathrm{dB}$ with standard deviation $\sigma_{s}$ which is also in dB.

The statistical analysis of $S$ gives $\sigma_{S}=1.1$ for LOS and $\sigma_{S}$ $=2.94$ for NLOS, respectively. The cumulative distribution function (cdf) of the deviation between the fitted and measured data is plotted versus the normal cdf (Figures 6 and 7). These curves show that the shadow fading is lognormally distributed.

\subsection{Dispersions properties of UWB channel}

The dispersive properties of the UWB channel can be considered as an extension of the large-scale study of the channel. There are two parameters to be characterized and analyzed. These parameters are the RMS delay spread $\tau_{\mathrm{rms}}$ and mean excess delay $\tau_{m}$. These two important parameters are used to characterize the temporal dispersive properties of the multipath channels. This is useful to estimate the performance and potential for ISI.

\subsubsection{Mathematical model}

The discrete mathematical model used for the complex impulse response is that of a linear filter with variable complex weights and variable delays and is given by

$$
h(d, t, \tau)=\sum_{k=1}^{N} a_{k}(d, t) \delta\left(t-t_{k}(d, t)\right) e^{j \theta_{k}(d, t)},
$$

where $N$ is the number of resolvable multipath components, $a_{k}, t_{k}, \theta_{k}$ are random amplitude, delay time (arrival-time), and phase sequences, respectively, and $\delta$ is the Dirac delta function.

By obtaining adequate statistical modeling of these random variables, we can offer a complete description of the

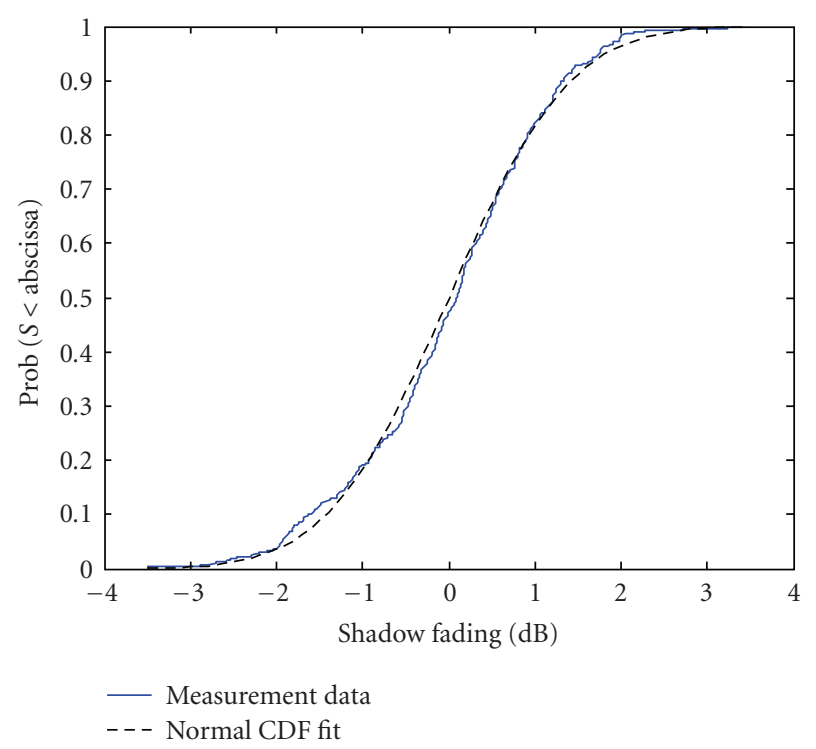

FIGURE 6: CDF of shadowing fading fit for normal distribution-LOS scenario.

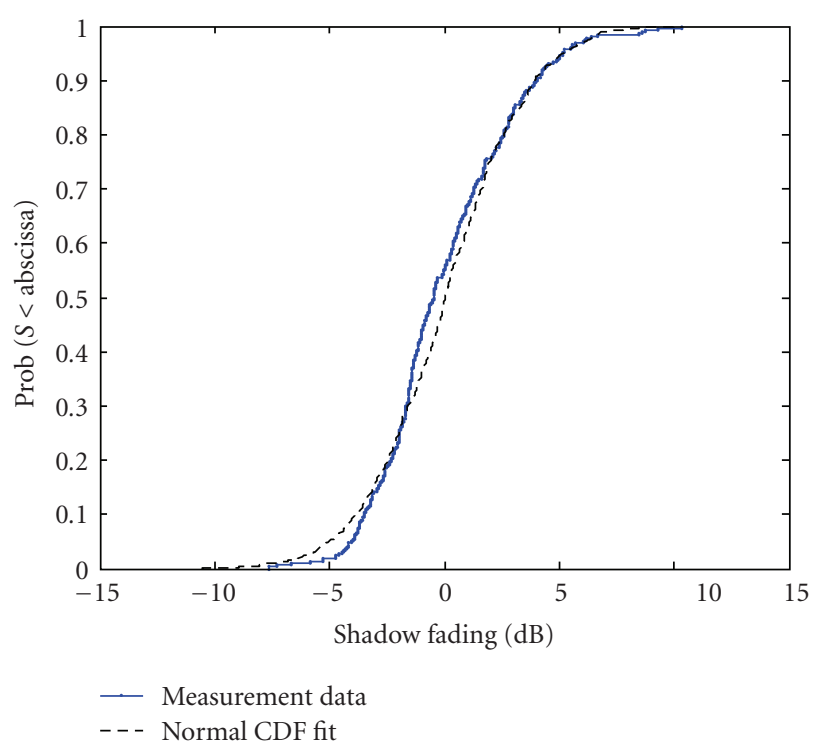

FIGURE 7: CDF of shadowing fading fit for normal distributionNLOS scenario.

multipath channel. $d$ represents the measurement location, while $t$ is the measurement instant. While $d$ varies according to different locations, $t$ will not be taken into consideration since measurements were without interference of any moving objects (persons or vehicular) and with stationary Tx and Rx.

According to this model, the received signal is the convolution of the transmitted signal with the complex impulse response, added with the channel noise, usually modeled as a complex Gaussian process.

In addition to the statistical information concerning the above random variables, another important parameter is extracted, namely, the RMS delay spread $\left(\tau_{\mathrm{rms}}\right)$. It is a onenumber representation of the multipath channel computed 


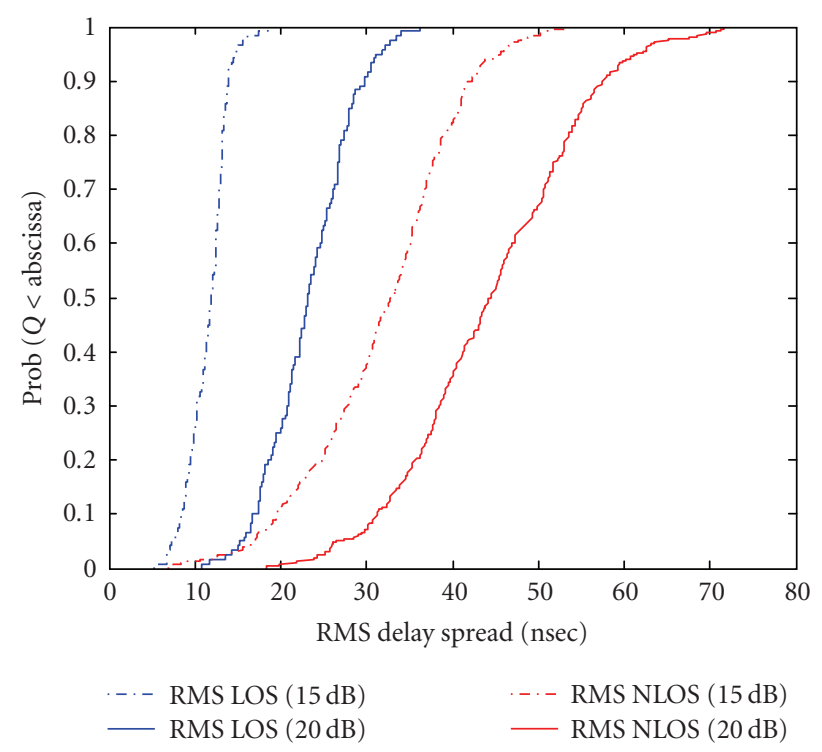

FIgURE 8: CDF of RMS delay spread values over LOS and NLOS cases.

from its complex impulse response that gives an estimation of the amount of intersymbol interference (ISI) to be encountered in the channel.

Many researchers have reported results concerning the measurement of $\tau_{\mathrm{rms}}$ for UWB channel in indoor environment [9-11], residential [12-14], and in industrial environment [16]. It is computed using

$$
\tau_{\mathrm{rms}}=\sqrt{\frac{\sum_{k=1}^{N} a_{k}^{2} \cdot\left(\tau_{k}-\tau_{f}-\tau_{m}\right)^{2}}{\sum_{k=1}^{N} a_{k}^{2}}},
$$

where $\tau_{f}$ is the arrival time of the first multipath component to rise above the predefined threshold, $\tau_{k}$ is the arrival time sequence of the multipath components, and $\tau_{m}$ is the average excess delay computed from the formula:

$$
\tau_{\mathrm{m}}=\frac{\sum_{k=1}^{N} a_{k}^{2} \cdot\left(\tau_{k}-\tau_{f}\right)}{\sum_{k=1}^{N} a_{k}^{2}} .
$$

It is clear for (5) and (6) that $\tau_{\mathrm{rms}}$ is the square root of the second central moment of the power-weighted delay profile.

\subsection{2. $R M S$ delay spread and mean excess delay}

The channel parameters RMS delay spread and mean excess delay are computed for each received profile at every location of the receiver in LOS and NLOS cases. Figure 8 shows the cumulative distribution function (cdf) of the variations in RMS delay spread for LOS and NLOS with two different thresholds. (The arrival time of the first path can be found by applying a threshold to the peak of the received signal. For our study, we used two different thresholds (e.g., $15 \mathrm{~dB}$ and $20 \mathrm{~dB})$ ).

The maximum variations in the RMS delay spread for LOS environment were about 11.8 nanoseconds for $15 \mathrm{~dB}$

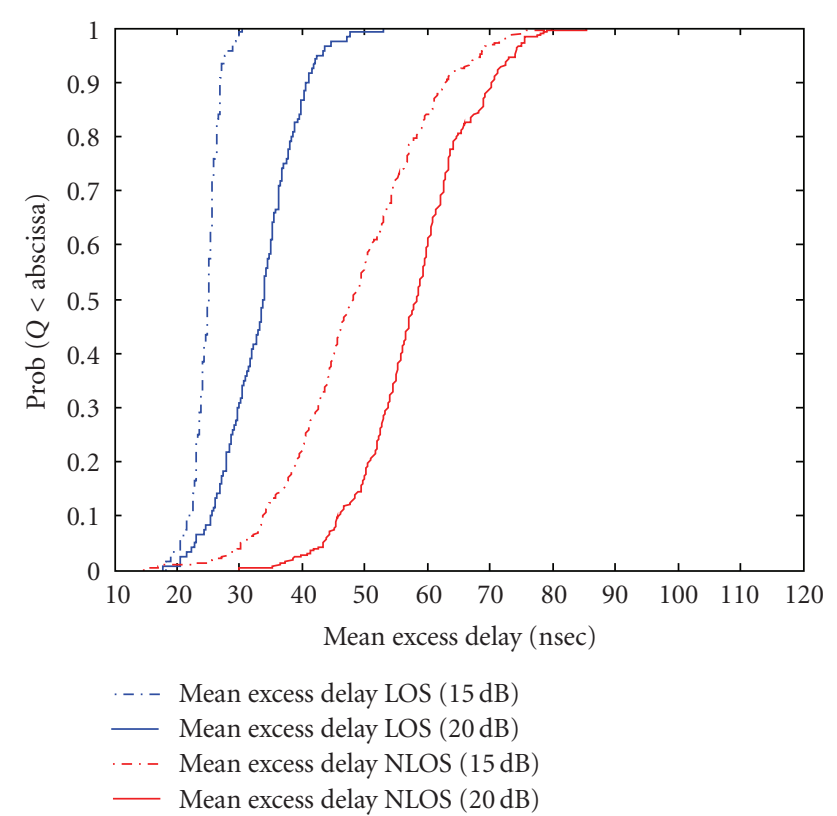

FIGURE 9: CDF of mean excess delay values over LOS and NLOS cases.

TABLE 1: Average values of $\tau_{\text {rms }}$ and $\tau_{m}$ (in nanosecond).

\begin{tabular}{lcccc}
\hline & \multicolumn{2}{c}{$\tau_{\text {rms }}$} & \multicolumn{2}{c}{$\tau_{m}$} \\
& $\mu_{\tau_{\mathrm{rms}}}$ & $\sigma_{\tau_{\mathrm{rms}}}$ & $\mu_{\tau_{m}}$ & $\sigma_{\tau_{m}}$ \\
\hline LOS $(15 \mathrm{~dB})$ & 11.8 & 4.4 & 22.61 & 3.4 \\
LOS $(20 \mathrm{~dB})$ & 23.6 & 5.14 & 33.76 & 5.72 \\
NLOS $(15 \mathrm{~dB})$ & 29.07 & 8.8 & 49.42 & 12.04 \\
NLOS $(20 \mathrm{~dB})$ & 44.38 & 10.6 & 58.30 & 8.46 \\
\hline
\end{tabular}

and 23.6 nanoseconds, for $20 \mathrm{~dB}$. For NLOS environment, they were about 29.07 nanoseconds $(15 \mathrm{~dB})$ and 44.38 nanoseconds $(20 \mathrm{~dB})$. This indicates that NLOS channels are subject to high-spatial variations of the RMS delay spread. This could be attributed to the presence of more scatterers, and hence more paths in NLOS environments than in LOS environments. The variation of the mean excess delay also indicates a similar pattern. Figure 9 shows the CDF of the mean excess delay. The variations of RMS and mean excess were summarized in Table 1.

\subsubsection{Variation of RMS delay spread}

Dependence of $\tau_{\text {rms }}$ on the transmitter-receiver separation is an important result, which if established can greatly influence system design. A review of previous works shows disagreement on this topic. Some measurements for wideband indoor channel have shown correlation between $\tau_{\text {rms }}$ and $\mathrm{Tx} / \mathrm{Rx}$ separation [17], while others indicate no correlation [18].

The time dispersion parameters of our measurements are plotted versus transmitter-receiver separation in Figures 10 and 11 . While some researchers in UWB channel measurements $[9,19]$ reported a correlation between distance and delay spread, no such correlation is evident from our 


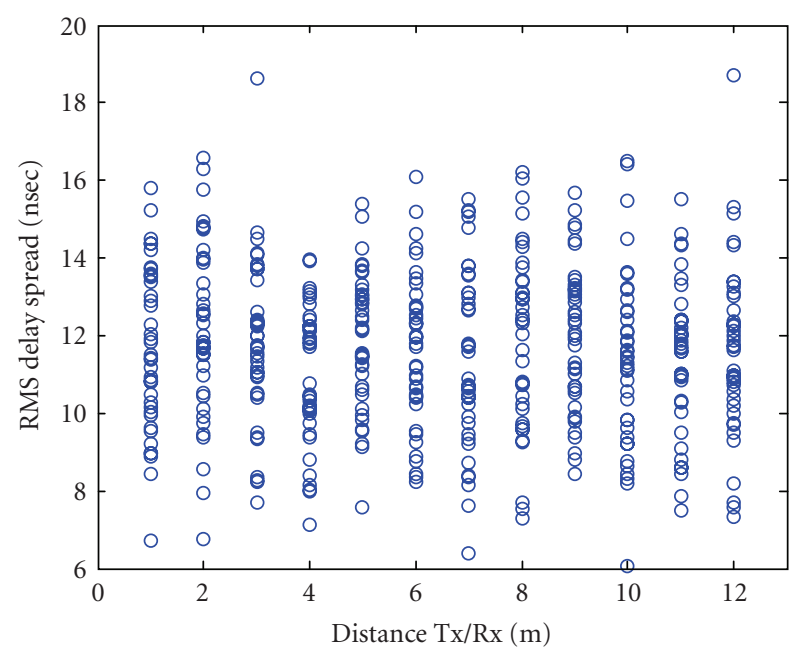

Figure 10: RMS delay spread versus distance, LOS (15 dB threshold).

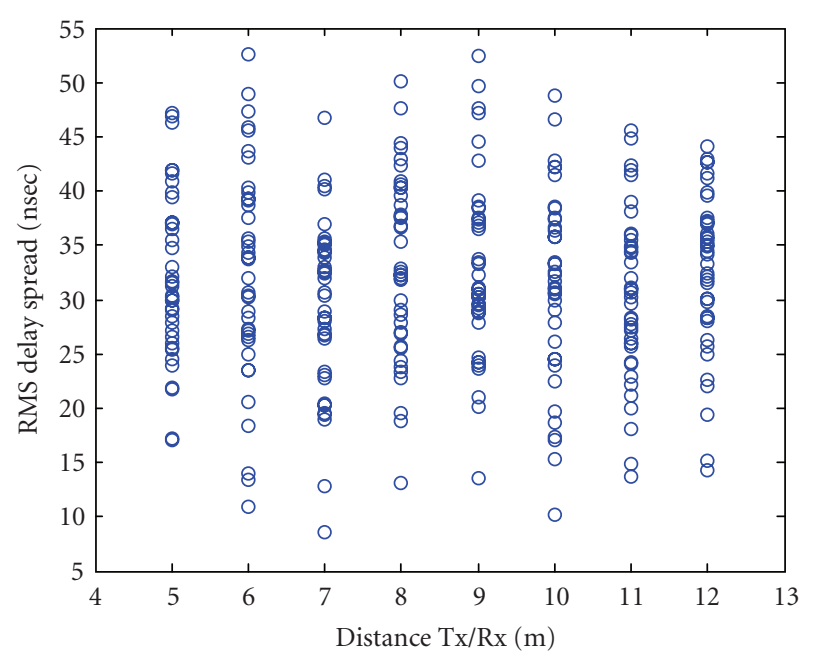

FIgURE 11: RMS delay spread versus distance, NLOS (15 dB threshold).

data sets. Therefore, since these data sets represent a fairly diverse set of environments, it is concluded that for the specific environments and distances considered, the physical environment has a much more significant impact on the time dispersive nature of the channel than the distance. For the underground gallery considered, random reflections have the effect of flattering the relationship between RMS delay spread and distance.

The RMS delay spread values are plotted versus the corresponding mean excess delay values. As shown in Figures 12 and 13 no definite correlation of the variation mean excess delay could be established.

\section{COMPARISONS WITH UWB AND PUBLISHED WIDEBAND RESULTS}

Many measurement campaigns and channel modeling efforts have been performed to characterize the UWB channel.

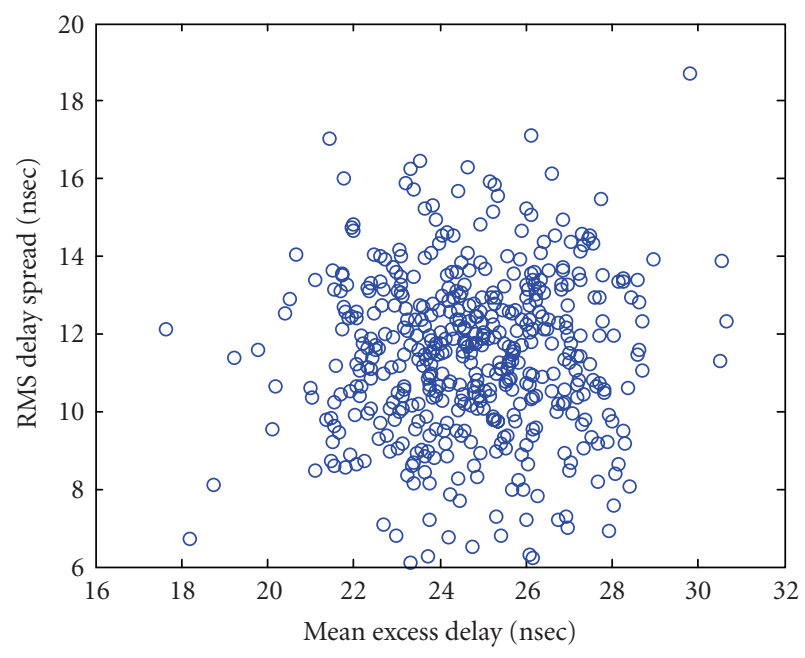

FIGURE 12: RMS delay spread versus mean excess delay, all channels, LOS (15 dB threshold).

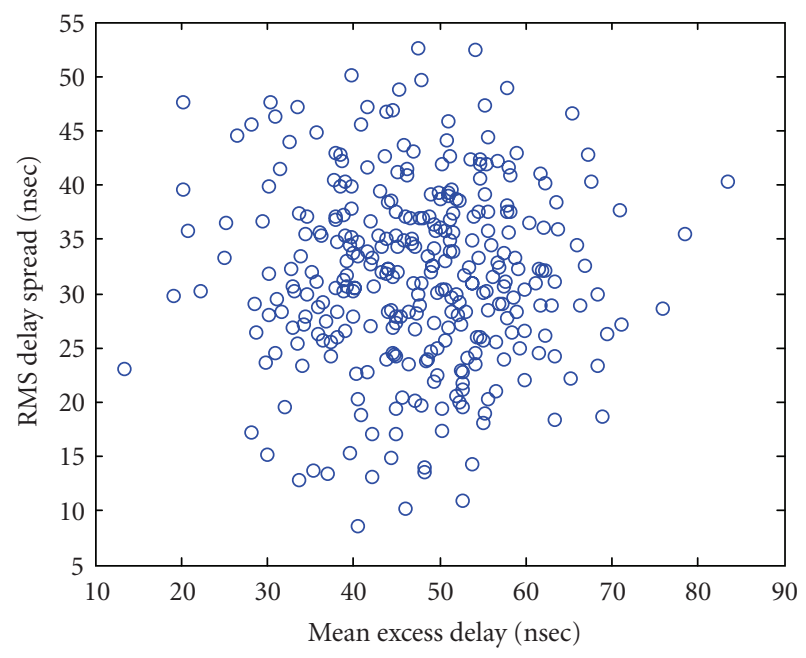

FIGURE 13: RMS delay spread versus mean excess delay, all channels, NLOS (15 dB threshold).

Several researchers have performed frequency-domain measurements using vector network analyzers. Moreover, a few time-domain, direct-pulse measurement systems have been used for UWB channel sounding. However, it is difficult to give a global comparison between our measurement and other published works (depending on the measurement environments, scenarios, frequency bandwidth, etc.). Hence, in this following subsection, we are interesting to give an overview about UWB channel measurement.

\subsection{Comparison with other UWB large-scale modeling}

The reported path loss exponents for narrowband systems are between 1.6 and 1.8 for inbuilding LOS environments and between 4 and 6 for obstructed inbuilding environments [29].

The path loss exponents for UWB are comparable with the path loss exponents for narrowband LOS scenarios, but 
TABLE 2: The reported values on large scale fading based on previous measurement campaigns.

\begin{tabular}{|c|c|c|c|c|c|c|c|}
\hline \multirow{2}{*}{ Source } & \multicolumn{2}{|c|}{ Path loss exponent } & \multicolumn{2}{|c|}{ Shadow fading } & \multirow{2}{*}{ Frequency range $(\mathrm{GHz})$} & \multirow{2}{*}{ Range (m) } & \multirow[t]{2}{*}{ Environment } \\
\hline & LOS & NLOS & LOS & NLOS & & & \\
\hline AT\&T [9] & 1.7 & 3.5 & 2.8 & 4.4 & $4.375-5.625$ & $1-15$ & Residential \\
\hline $\begin{array}{l}\text { France } \\
\text { Telecom [10] }\end{array}$ & 1.62 & 3.22 & 1.7 & 5.5 & $3.1-10.6$ & $1-20$ & Office \\
\hline $\begin{array}{l}\text { Virginia Tech } \\
{[11]}\end{array}$ & $1.3-1.4$ & 2.3-2.4 & $2.5-3$ & $2.6-5.6$ & Time domain & $\begin{array}{l}5-49(\mathrm{LOS}) \\
2-9(\mathrm{NLOS})\end{array}$ & Laboratory \\
\hline Intel [12] & 1.72 & 4.09 & 1.48 & 3.63 & $2-8$ & $\begin{array}{l}1-11 \text { (LOS) } \\
4-15 \text { (NLOS) }\end{array}$ & Residential \\
\hline Samsung [14] & 1.8 & 2.18 & 0.98 & 1.43 & $3.1-10.6$ & $1-20$ & Residential \\
\hline $\begin{array}{l}\text { New jersey } \\
\text { Institute [15] }\end{array}$ & $1.55-1.65-1.77$ & - & $1.98-1.19-0.77$ & - & $2-6$ & $1-10$ & Laboratory \\
\hline $\begin{array}{l}\text { CEA-LETI } \\
{[20]}\end{array}$ & 1.63 & 3.68 & - & - & $2-6$ & $\begin{array}{l}1.6(\mathrm{LOS}) \\
3-20(\mathrm{NLOS})\end{array}$ & Residential \\
\hline U.C.A.N [21] & 1.4 & $\begin{array}{l}3.2 \text { (soft) } \\
4.1 \text { (hard) }\end{array}$ & 0.35 & $\begin{array}{l}1.21 \text { (soft) } \\
1.87 \text { (hard) }\end{array}$ & - & $4-14$ & Office \\
\hline $\begin{array}{l}\text { ETH Zurich } \\
{[22]}\end{array}$ & $\begin{array}{r}2.7-3.3(\mathrm{c} \\
4.1 \text { (a round }\end{array}$ & $\begin{array}{l}\text { body) } \\
\text { the torso) }\end{array}$ & - & - & $3-6$ & $0.5-1.5$ & Body \\
\hline $\begin{array}{l}\text { Cassioli/ } \\
\text { Molisch/Win } \\
{[23]}\end{array}$ & $\begin{array}{r}2.04(d< \\
56+74 \log (d)\end{array}$ & $\begin{array}{l}11 \mathrm{~m}) \\
(d>11 \mathrm{~m})\end{array}$ & - & - & Time domain & $\begin{array}{l}8-11,11-13 \\
\text { (NLOS) }\end{array}$ & Indoor \\
\hline $\begin{array}{l}\text { Oulu Univ. } \\
{[24]}\end{array}$ & $1.04-1.4-1.8$ & $3.2-3.3-3.9$ & - & - & $2-6$ & $\begin{array}{l}1-30 \text { (LOS) } \\
4-14 \text { (NLOS) }\end{array}$ & Indoor \\
\hline Whyless [25] & 1.58 & 1.96 & - & - & $1-11$ & $\begin{array}{l}2-5(\mathrm{LOS}) \\
1-6(\mathrm{NLOS})\end{array}$ & Office \\
\hline DARPA [26] & 1.3 & 2.3 & 2.6 & 2.4 & Time domain & 10 & Laboratory \\
\hline $\begin{array}{l}\text { Oulu Univ. } \\
{[27]}\end{array}$ & 1.62 & - & - & - & $3.1-6$ & 3-6 (LOS) & Hospital \\
\hline $\begin{array}{l}\text { Aquila Univ } \\
\text { [28] }\end{array}$ & $2.5-2.6$ & - & $2.11-5.23$ & - & Time domain & $1-25$ & Forest \\
\hline LRCS & 1.47 & 2.45 & 1.1 & 2.95 & $2-5$ & $\begin{array}{l}1-12 \quad(L O S) \\
5-12(\text { NLOS })\end{array}$ & $\begin{array}{l}\text { Underground } \\
\text { mines }\end{array}$ \\
\hline
\end{tabular}

are smaller for NLOS scenarios. In [11], the reported pathloss exponent was as low as 1.27 for a narrow corridor. For LOS and NLOS scenarios, the global path-loss exponents were found to be nearly 1.6 and 2.7, respectively. According to [12], the PL exponent and the SDS for LOS are 1.7 and $1.5 \mathrm{~dB}$, respectively, and for NLOS 4.1 and $3.6 \mathrm{~dB}$, respectively.

In [14], the reported values of $n$ for $\mathrm{Tx} / \mathrm{Rx}$ separation ranging from 1 to $20 \mathrm{~m}$ are $1.18,2.18,2.48$, and 2.69 for LOS (three-bedroom apartment), NLOS (three-bedroom apartment), LOS (four-bedroom apartment), and NLOS (four-bedroom apartment), respectively. According to [30], the $P L$ exponent and the standard deviation of shadowing (SDS) are 2.4 and $5.9 \mathrm{~dB}$, respectively, and the best model for shadowing is the log-normal distribution. The $P L$ exponent is reported in [31] as 1.7 and 3.5 and for the SDS as $1.6 \mathrm{~dB}$ and $2.7 \mathrm{~dB}$ for LOS and NLOS, respectively. Some other reported values on path loss exponent and standard deviation of shadowing based on previous measurement campaigns are summarized in Table 2.

\subsection{Comparison with other UWB time dispersion parameters}

In the 5-30 $\mathrm{m}$ range, indoor channels are expected to have an RMS delay spread of 19-47 nanoseconds [32] and mean values in the range of 20-30 nanoseconds [33]. For example, Keignart and Daniele [34] presented their measurements for a maximum range of $10 \mathrm{~m}$ in an indoor UWB channel. They found that their measured RMS delay spread varies between 14 and 18 nanoseconds which is lower than what was reported by Hashemi and Tholl [33]. They also found that the mean excess delay increases when transmitter-receiver antenna separation increases.

Some published works [32] suggest that a fairly conservative RMS delay spread of 25 nanoseconds would be a good initial starting point for personal area network- (PAN-) type applications with antenna separations of about $10 \mathrm{~m}$ or less.

The RMS delay spread seems to follow a normal distribution $[12,31,34]$. For the LOS case, in [12] $\mu_{\mathrm{rms}}=9$ nanoseconds, in [31] $\mu_{\mathrm{rms}}=4.7$ nanoseconds, and $\sigma_{\mathrm{rms}}=2.3$ 
TABLE 3: Results about time-domain parameters in previous measurement campaigns for LOS case.

\begin{tabular}{|c|c|c|c|c|c|}
\hline Source & $\tau_{\mathrm{rms}}$ & $\tau_{m}$ & Frequence range $(\mathrm{GHz})$ & Range $(\mathrm{m})$ & Environment \\
\hline AT\&T [9] & 4.7 & - & $4.375-5.625$ & $1-15$ & Residential \\
\hline France Telecom [10] & 4.1 & - & $3.1-10.6$ & $1-20$ & Office \\
\hline Virginia Tech [11] & 5.41 & 5.19 & Time domain & $5-49$ & Laboratory \\
\hline Intel [12] & 9 & 3 & 2-8 & $1-11$ & Residential \\
\hline Samsung [14] & $12.48-14$ & $5.01-5.88$ & $3.1-10.6$ & $1-20$ & Residential \\
\hline New Jersey Inst. [15] & 17.34 & 11.86 & $2-6$ & $1-10$ & Laboratory \\
\hline Mitsubishi [16] & $28-31$ & - & $3-10$ & $2-8$ & Industrial \\
\hline CEA-LETI [20] & 10.07 & 6.42 & $2-6$ & 4 & Laboratory \\
\hline IKT, ETH Zurich [22] & $1.4-2.1,2.2-7.5$ & $1.2-1.4,4.7-11.3$ & $0.5-1.5$ & $3-6$ & Body \\
\hline Aquila Univ. [28] & $5-11$ & $1-4.5$ & Time domain & $1-25$ & Forest \\
\hline LRCS & 11.8 & 22.61 & $2-5$ & $1-12$ & Underground mines \\
\hline
\end{tabular}

TABLE 4: Results about time-domain parameters in previous measurement campaigns for NLOS case.

\begin{tabular}{lccccc}
\hline Source & $\tau_{\text {rms }}$ & $\tau_{m}$ & Frequence range $(\mathrm{GHz})$ & Range $(\mathrm{m})$ & Environment \\
\hline AT\&T [9] & 8.2 & - & $4.375-5.625$ & $1-15$ & Residential \\
France Telecom [10] & 9.9 & - & $3.1-10.6$ & $1-20$ & Office \\
Virginia Tech [11] & 13.7 & 16 & Time domain & $2-9$ & $4-15$ \\
Intel [12] & 11.5 & 10 & $3.1-10.6$ & $1-20$ & Residential \\
Samsung [14] & $26.51-38.61$ & $24.95-$ & $2-6$ & $4-10$ & Residential \\
CEA-LETI [20] & 14.78 & 16.01 & $3-6$ & $0.15-0.28$ & Laboratory \\
IKT, ETH Zurich [22] & $1.4-2.1,7.3-9.9$ & $1.1-1.3$ & $5-12$ & Body \\
LRCS & 29.07 & 49.42 & $2-5$ & & Underground mines \\
\hline
\end{tabular}

nanoseconds, and in [34] $\mu_{\mathrm{rms}}=2-12$ nanoseconds and $\sigma_{\mathrm{rms}}$ $=3.3$ nanoseconds are reported. For NLOS case, in [12] $\mu_{\mathrm{rms}}$ $=11.5$ nanoseconds, in [31] $\mu_{\mathrm{rms}}=8.2$ nanoseconds and $\sigma_{\mathrm{rms}}$ $=3.3$ nanoseconds and in [34] $\mu_{\mathrm{rms}}=14-19$ nanoseconds and $\sigma_{\text {rms }}=1-5$ nanoseconds, are reported. Tables 3 and 4 present an illustration of reported results in the literature for the RMS delay spread, $\tau_{\mathrm{rms}}$, the mean excess delay, $\tau_{m}$.

\subsection{Comparisons with narrowband and wideband channel in underground mines}

Other results have been published for the characterization of narrowband and wideband channel in the underground mine environment. Nerguizian et al. [35] found that the path loss is equal to 2.16 with a standard deviation of 6.13 ; the shadow fading was not presented. The authors also showed that the RMS delay spread is about 27 nanoseconds with a 23.5-standard deviation. Liénard and Degauque [36] have observed RMS delay spreads of 19 nanoseconds in LOS conditions in their underground mine gallery and of 25 nanoseconds to 42 nanoseconds in NLOS conditions. Hämäläinen et al. [37] have observed that the total delay spread does not exceed 500 nanoseconds.

\section{SUMMARY AND CONCLUSION}

In this paper, an analysis of large-scale fading and time dispersion parameters (RMS delay spread and mean excess delay) of the UWB channel in an underground environment was presented.

The measurements were made in a laboratory mine. We have seen that in the case of large-scale modeling, propagation in an underground mine can be modeled (path loss exponent, and shadow fading) as other channel model found in the literature. However, the parameters are quite different. The path loss exponent was found to be lower than the free-space attenuation (i.e., $n=2$ ) for the LOS situation because of the additional received power caused by reflections.

Furthermore, we found that the variation of the received signal power around the theoretical model follows a lognormal distribution. The mean standard deviation of shadow fading (in $\mathrm{dB}$ ) was found to be $\sigma_{S}=1.1$ for LOS and $\sigma_{S}=$ 2.94 for NLOS, respectively.

The results show that the values of RMS delay spread are 11.8 nanoseconds (29.07 nanoseconds) for LOS (NLOS). In both cases, these values are much smaller compared to 
those of conventional narrowband systems in similar environments. This means that high-data rates can be achieved in underground mines using UWB. However, unlike some interesting applications using UWB (e.g., tracking and geolocation) which need low to moderate date rates, others applications (e.g., IP video, wireless camera) which need high-date rates can be deployed in underground mines. Hence, UWB is considered as a good candidate for all these applications.

In the next few years, UWB will become a viable, competitive wireless technology. In Fact, UWB-wireless communication can potentially improve process operations, product quality, and productivity, boost the safety of mining and improve rescue operations during disasters.

We have also seen that there is no correlation between the RMS delay spread and the $\mathrm{Rx} / \mathrm{Tx}$ separation. This particular property can be explained by the direct effect of scatterers in underground mines (summarized in Section 2). These last ones have a much more significant impact on the time dispersive nature of the channel than the distance between transmitter and receiver. Hence, for the underground gallery considered, random reflections have the effect of flattening the relationship between RMS delay spread and distance.

The results presented herein (with other works) are currently exploited in the design of wireless local area networks communication and for localization applications in underground mining environments.

\section{ACKNOWLEDGMENTS}

This work was done with support of Université du Québec en Abitibi Témiscamingue (UQAT). The author would like to acknowledge the continuing guidance of LRCS laboratory. The authors also wish to thank the personnel of MMSLCANMET (Mining and Mineral Sciences LaboratoriesCanadian Center for Minerals and Energy Technology) experimental mine.

\section{REFERENCES}

[1] S. Outalha, R. Le, and P. M. Tardif, "Toward a unified and digital communication system for underground mines," CIM Bulletin, vol. 93, no. 1044, pp. 100-105, 2000.

[2] L. Yang and G. B. Giannakis, "Ultra-wideband communications: an idea whose time has come," IEEE Signal Processing Magazine, vol. 21, no. 6, pp. 26-54, 2004.

[3] A. F. Molisch, "Ultrawideband propagation channels-theory, measurement, and modeling," IEEE Transactions on Vehicular Technology, vol. 54, no. 5, pp. 1528-1545, 2005.

[4] J. Foerster and Q. Li, "UWB channel modeling contribution from Intel," IEEE P802.15 Working Group for Wireless Personal Area Networks (WPANs), June 2002, http://www.ieee802.org/15/pub/2002/Jul02/02279r0P802-15_ SG3a-Channel-Model-Cont-Intel.doc.

[5] A. F. Molisch, K. Balakrishnan, C. C. Chong, et al., "IEEE 802.15.4a channel model-final report," Tech. Rep. IEEE P802.15-04/0662, WPANs, Attleboro, Mass, USA, November 2004, www.ieee802.org/15/pub/TG4a.html.

[6] A. Chehri, P. Fortier, H. Aniss, and P. M. Tardif, "UWB spatial fading and small scale characterization in underground mines," in Proceedings of the 23rd Biennial Symposium on
Communications, pp. 213-218, Kingston, Canada, May-June 2006.

[7] A. Chehri, P. Fortier, and P. M. Tardif, "Frequency domain analysis of UWB channel propagation in underground mines," in Proceedings of the IEEE 64th Vehicular Technology Conference (VTC '06), pp. 1-5, Montreal, Canada, September 2006.

[8] A. Chehri, P. Fortier, and P. M. Tardif, "Eigen-analysis of UWB channel on the basis of information theoretic criteria," in Proceedings of the IEEE International Conference on Communications (ICC '07), pp. 4891-4895, Glasgow, Scotland, June 2007.

[9] S. S. Ghassemzadeh, R. Jana, C. W. Rice, W. Turin, and V. Tarokh, "Measurement and modeling of an ultra-wide bandwidth indoor channel," IEEE Transactions on Communications, vol. 52, no. 10, pp. 1786-1796, 2004.

[10] P. Pagani and P. Pajusco, "Statistical modeling of the ultra wide band propagation channel through the analysis of experimental measurements," Comptes Rendus Physique, vol. 7, no. 7, pp. 762-773, 2006.

[11] A. Muqaibel, A. Safaai-Jazi, A. Attiya, B. Woerner, and S. Riad, "Path-loss and time dispersion parameters for indoor UWB propagation," IEEE Transactions on Wireless Communications, vol. 5, no. 3, pp. 550-559, 2006.

[12] L. Rusch, C. Prettie, D. Cheung, Q. Li, and M. Ho, "Characterization of UWB propagation from 2 to $8 \mathrm{GHz}$ in a residential environment," [Online]. Available: http://www.intel.com/.

[13] S. S. Ghassemzadeh, L. J. Greenstein, A. Kavčić, T. Sveinsson, and V. Tarokh, "UWB indoor path loss model for residential and commercial buildings," in Proceedings of the 58th IEEE Vehicular Technology Conference (VTC '03), vol. 5, pp. 31153119, Orlando, Fla, USA, October 2003.

[14] C.-C. Chong, Y. Kim, and S.-S. Lee, "Statistical characterization of the UWB propagation channel in various types of high-rise apartments," in Proceedings of the IEEE Wireless Communications and Networking Conference (WCNC'05), vol. 2, pp. 944-949, New Orleans, La, USA, March 2005.

[15] J. A. Dabin, N. Ni, A. M. Haimovich, E. Niver, and H. Grebel, "The effects of antenna directivity on path loss and multipath propagation in UWB indoor wireless channels," in Proceedings of the IEEE Conference on Ultra Wideband Systems and Technologies (UWBST '03), pp. 305-309, Reston, Va, USA, November 2003.

[16] J. Karedal, S. Wyne, P. Almers, F. Tufvesson, and A. F. Molisch, "Statistical analysis of the UWB channel in an industrial environment," in Proceedings of the 60th IEEE Vehicular Technology Conference (VTC '04), vol. 1, pp. 81-85, Los Angeles, Calif, USA, September 2004.

[17] R. J. C. Bultitude, "Measurement of wideband propagation characteristics for indoor radio with predictions for digital system performance," in Proceedings of the Wireless '90 Conference, Calgary, Canada, July 1990.

[18] A. Saleh and R. Valenzuela, "A statistical model for indoor multipath propagation," IEEE Journal on Selected Areas in Communications, vol. 5, no. 2, pp. 128-137, 1987.

[19] K. Siwiak, H. Bertoni, and S. M. Yano, "Relation between multipath and wave propagation attenuation," Electronics Letters, vol. 39, no. 1, pp. 142-143, 2003.

[20] J. Keignart, N. Daniele, J.-B. Pierrot, and P. Rouzet, "UWB channel modeling contribution from CEA-LETI and STMicroelectronics," IEEE P802.15-02/444sG3a, October 2002.

[21] Á. Álvarez, G. Valera, M. Lobeira, R. Torres, and J. L. García, "New channel impulse response model for UWB indoor system simulations," in Proceedings of the 57th IEEE 
Semiannual Vehicular Technology Conference (VTC '03), vol. 1, pp. 1-5, Jeju, Korea, April 2003.

[22] T. Zasowski, F. Althaus, M. Stäger, A. Wittneben, and G. Tröster, "UWB for noninvasive wireless body area networks: channel measurements and results," in Proceedings of the IEEE Conference on Ultra Wideband Systems and Technologies (UWBST'03), pp. 285-289, Reston, Va, USA, November 2003.

[23] D. Cassioli, M. Z. Win, and A. F. Molisch, "The ultra-wide bandwidth indoor channel: from statistical model to simulations," IEEE Journal on Selected Areas in Communications, vol. 20, no. 6, pp. 1247-1257, 2002.

[24] V. Hovinen, M. Hämäläinen, R. Tesi, L. Hentilä, and N. Laine, "A proposal for a selection of indoor UWB path loss model," Tech. Rep. IEEE P802.15-02/280-SG3a, Wisair, Tel Aviv, Israel, July 2002, http://grouper.ieee.org/groups/ 802/15/pub/2002/Jul02.

[25] J. Kunisch and J. Pamp, "Measurement results and modeling aspects for UWB radio channel," in Proceedings of the IEEE Conference on Ultra Wideband Systems and Technologies (UWBST '02), pp. 19-23, Baltimore, Md, USA, May 2002.

[26] B. M. Donlan, D. R. McKinstry, and R. M. Buehrer, "The UWB indoor channel: large and small scale modeling," IEEE Transactions on Wireless Communications, vol. 5, no. 10, pp. 2863-2872, 2006.

[27] L. Hentilä, A. Taparungssanagorn, H. Viittala, and M. Hämäläinen, "Measurement and modelling of an UWB channel at hospital," in Proceedings of the IEEE International Conference on Ultra-Wideband (ICU'05), pp. 113-117, Zurich, Switzerland, September 2005.

[28] M. Di Renzo, F. Graziosi, R. Minutolo, M. Montanari, and F. Santucci, "The ultra-wide bandwidth outdoor channel: from measurement campaign to statistical modelling," Mobile Networks \& Applications, vol. 11, no. 4, pp. 451-467, 2006.

[29] T. S. Rappaport, Wireless Communications: Principles and Practice, Prentice-Hall, Upper Saddle River, NJ, USA, 2002.

[30] D. Cassioli, M. Z. Win, and A. F. Molisch, "A statistical model for the UWB indoor channel," in Proceedings of the 53rd IEEE Vehicular Technology Conference (VTC '01), vol. 2, pp. 11591163, Rhodes, Greece, May 2001.

[31] S. S. Ghassemzadeh, R. Jana, C. W. Rice, W. Turin, and V. Tarokh, "A statistical path loss model for in-home UWB channels," in Proceedings of the IEEE Conference on Ultra Wideband Systems and Technologies (UWBST '02), pp. 59-64, Baltimore, Md, USA, May 2002.

[32] J. R. Foerster, "The effects of multipath interference on the performance of UWB systems in an indoor wireless channel," in Proceedings of the 53rd IEEE Vehicular Technology Conference (VTC '01), vol. 2, pp. 1176-1180, Rhodes, Greece, May 2001.

[33] H. Hashemi and D. Tholl, "Statistical modeling and simulation of the RMS delay spread of indoor radio propagation channels," IEEE Transactions on Vehicular Technology, vol. 43, no. 1, pp. 110-120, 1994.

[34] J. Keignart and N. Daniele, "Subnanosecond UWB channel sounding in frequency and temporal domain," in Proceedings of the IEEE Conference on Ultra Wideband Systems and Technologies (UWBST '02), pp. 25-30, Baltimore, Md, USA, May 2002.

[35] C. Nerguizian, C. L. Despins, S. Affès, and M. Djadel, "Radiochannel characterization of an underground mine at $2.4 \mathrm{GHz}$," IEEE Transactions on Wireless Communications, vol. 4, no. 5, pp. 2441-2453, 2005.

[36] M. Liénard and P. Degauque, "Natural wave propagation in mine environments," IEEE Transactions on Antennas and Propagation, vol. 48, no. 9, pp. 1326-1339, 2000.
[37] M. Hämäläinen, J. Talvitie, V. Hovinen, and P. Leppanen, "Wideband radio channel measurement in a mine," in Proceedings of the 5th IEEE International Symposium on Spread Spectrum Techniques and Applications (ISSSTA '05), vol. 2, pp. 522-526, Sun City, South Africa, September 1998. 

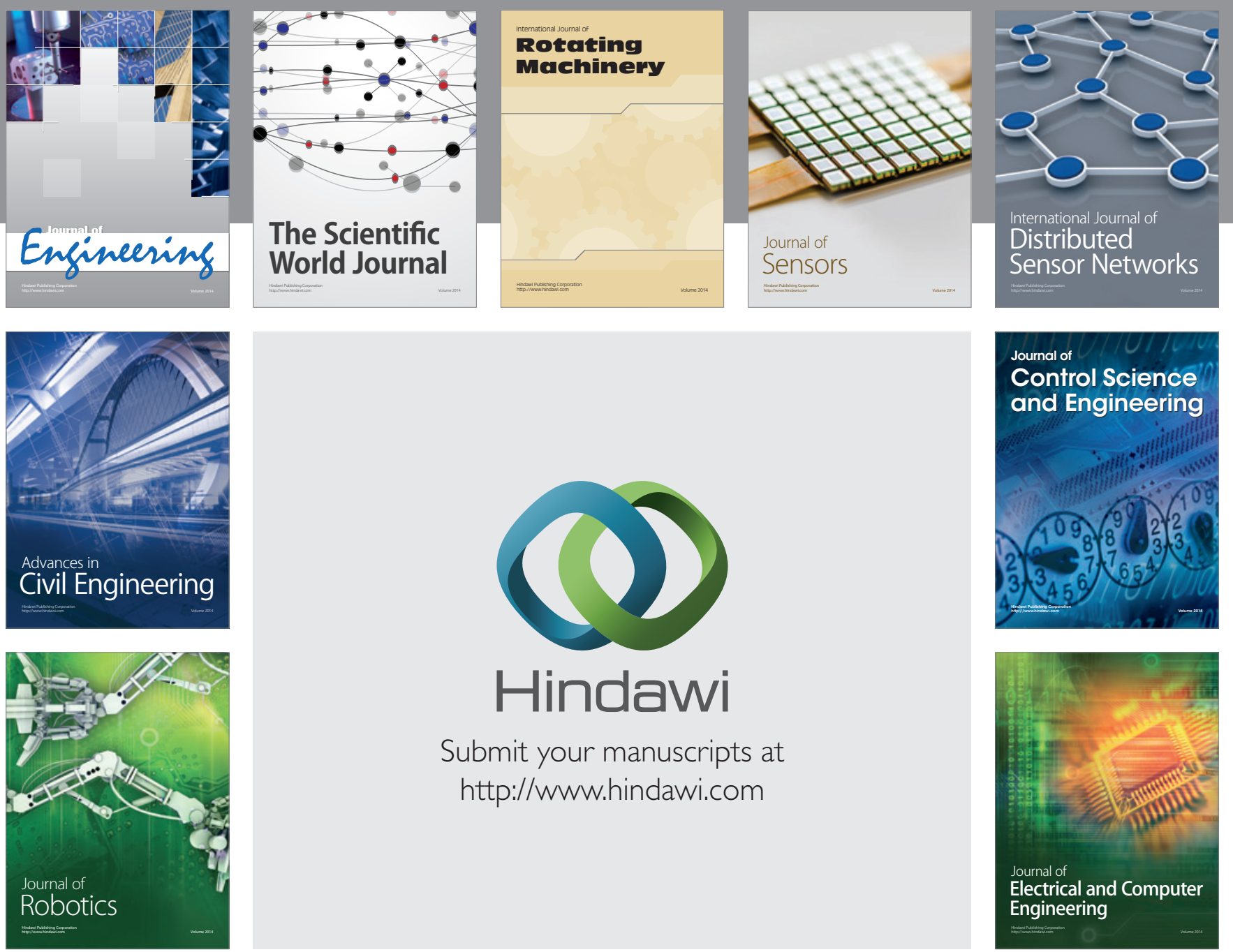

Submit your manuscripts at

http://www.hindawi.com
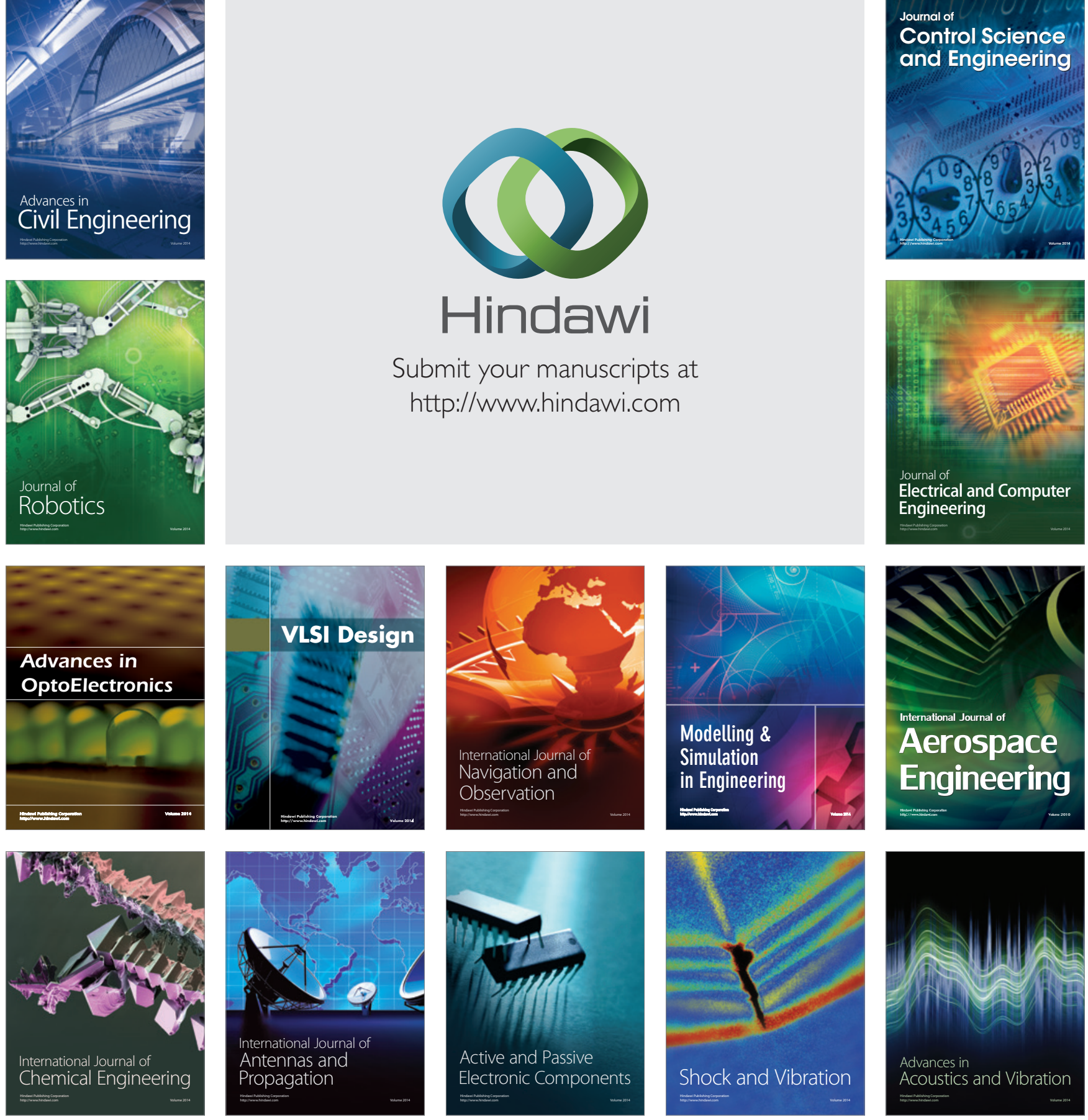